\title{
Modulation of Fatty Acid Oxidation and Glucose Uptake by Oxytocin in Adipocytes
}

\author{
Han-Jen Lin1, Yu-Shan Chen², Yu-Jen Chen'3, Yuan-Yu Lin1, Harry J. Mersmann1, Shih-Torng Ding1,3* \\ ${ }^{1}$ Department of Animal Science and Technology, National Taiwan University, Taiwan \\ ${ }^{2}$ Graduate Institute of Microbiology, National Taiwan University, Taiwan \\ ${ }^{3}$ Institute of Biotechnology, National Taiwan University, Taiwan \\ Email: ^sding@ntu.edu.tw
}

How to cite this paper: Lin, H.-J., Chen, Y.-S., Chen, Y.-J., Lin, Y.-Y., Mersmann, H.J. and Ding, S.-T. (2017) Modulation of Fatty Acid Oxidation and Glucose Uptake by Oxytocin in Adipocytes. J. Biomedical Science and Engineering, 10, 37-50. https://doi.org/10.4236/jbise.2017.102005

Received: December 29, 2016

Accepted: February 14, 2017

Published: February 17, 2017

Copyright $\odot 2017$ by authors and Scientific Research Publishing Inc. This work is licensed under the Creative Commons Attribution International License (CC BY 4.0).

http://creativecommons.org/licenses/by/4.0/

\section{(c) (i) Open Access}

\begin{abstract}
Oxytocin (OT) is a hypothalamic neuropeptide synthesized and secreted by OT neurons. In addition to its conventional role in reproductive physiology, central OT also regulates various social behaviors, such as care, trust, and emotions. Central and subcutaneous OT infusions stimulate lipid metabolism in mice and rats when fed standard or high fat diets. Mice lacking the OT receptor (OTR) or OT peptide develop late-onset obesity with greater fat pad weights, larger adipocyte size and elevated plasma levels of leptin. To study the effects of OT on lipid metabolism, we examined the effects of serial OT doses $(0,10,30,100,150,300 \mathrm{nM})$ on 3T3L1 adipocytes, together with long (144 hours, 6 days) and short ( 24 hours, 1 day) term treatments. The shortterm treatment with $150 \mathrm{nM}$ OT increased triacylglycerol (TAG) accumulation and decreased mRNA expressions of carnitine palmitoyltransferase $1 \alpha$ (CPT-1 $\alpha$ ) and fatty acid binding protein 4 (FABP4). After long-term incubation with $150 \mathrm{nM} \mathrm{OT}$, only the CPT-1 $\alpha$ mRNA was decreased. In differentiated adipocytes derived from pig adipose tissue stem cells, only hormone sensitive lipase mRNA was decreased after short- or long-term treatment with OT. To obtain further insight into the underlying mechanism of OT induction, we tested the involvement of the AKT/PKB pathway; however, AKT phosphorylation was decreased after treatment with $150 \mathrm{nM}$ OT, suggesting that OT effects may be independent from the AKT/PKB pathway. Taken together, OT effects on adipocyte glucose and lipid metabolism are probably through mechanisms other than the AKT/PKB pathway.
\end{abstract}

\section{Keywords}

Oxytocin, Lipid Metabolism, Glucose Uptake

\section{Introduction}

Oxytocin (OT) is a neuropeptide hormone which is mainly produced as a large 
precursor molecule in two hypothalamic nuclei, hypothalamic paraventricular (PVN) and supraoptic nuclei (SON) [1]. Plasma OT is increased with uterine contraction, milk ejection and maternal care in female mammals [2]. In addition, OT triggers learning and memory, social binding, regulation of emotional abilities and stress-related responses; OT may act as an endogenous antipsychotic in humans [3] [4] [5]. Furthermore, OT is a cardiovascular protective hormone for releasing atrial natriuretic peptide (ANP) to adjust blood volume and decrease heart rate of rats [6] [7] [8] [9]. Binding of OT to its receptor (OTR) results in the hydrolysis of phosphatidylinositol and release of cytosolic $\mathrm{Ca}^{2+}$ [10] leading to transcriptional activity by phosphorylation, activation of mitogen-activated protein kinases (MAPKs) and extracellular signal-regulated kinases (ERKs) [11].

Increase of OT in human and rodents has been seen in obese population or diabetic animal models [12] [13] [14]. Animals developed obesity when they were deficient of OT or OT receptors [15] [16]. Peripheral OT treatment reduced adipose tissue proportion and also ameliorated food intake, fatty liver, as well as glucose intolerance in ob/ob mice [17] [18] [19]. Adipocyte size was smaller after treating with OT, the lipogenic related genes fatty acid binding protein 4 (FABP4), peroxisomal proliferator activated receptor gamma (PPAR $\gamma$ ), glucose transporter 4 (GLUT4), and leptin mRNA levels in adipose tissues were increased in rats, indicating that $\mathrm{OT}$ treatment improves nutrient provision in adipose tissue [20]. OT exerted insulin-like effects in isolated adipocytes, as stimulation of glucose oxidation, lipogenesis and pyruvate dehydrogenase activity [21] [22]. Glucagon and insulin were released by OT stimulations in isolated pancreas and islets of rodents [23] [24]. Daily peripheral injection and infusion of OT improved glucose tolerance test in mice with high-fat diet feeding [17] [25]. OT increased glucose uptake of cardiomyocytes through AKT/PKB phosphorylation in rodent [8] [26]. Therefore, it's believed that OT may have the function of anti-obesity. However, the detail regulated signaling pathway under OT stimulation has not been defined. Here, we used the adipocyte cell culture model to demonstrate how OT regulating gene expression is related to lipid and carbohydrate utilization.

We confirmed that the OT receptor and insulin receptor mRNAs are expressed in 3T3L1 adipocytes by real-time PCR analysis. We also demonstrated that OT influences both uptake and utilization of lipid and carbohydrates, as well as energy accumulation within adipocytes. The AKT/PKB signaling pathway did not seem to be involved in the OT regulation of lipid and glucose metabolism in adipocytes.

\section{Materials and Methods}

\subsection{Cell Culture}

The 3T3L1 cell line was purchased from ATCC (Manassas, VA, USA) and cultured by Dulbecco's Modified Eagle's Medium (DMEM, 12800-017, Gibco, ThermoFisher, Waltham, MA) with 10\% calf serum (16010-159, Gibco, Ther- 
moFisher, Waltham, MA), 1\% Pen-Strep Ampho. Solution (PSA; Penicillin, $10^{5}$ units/L; Streptomycin, 100 mg/L; Amphotericin B, 0.25 mg/L, \#03-033-1B, Biological Industries, Cromwell, CT, USA) in the incubator at $37^{\circ} \mathrm{C}$ with $5 \% \mathrm{CO}_{2}$ in air and $100 \%$ of relative humidity. We seeded 3T3L1 cells $\left(2 \times 10^{5} / \mathrm{cm}^{2}\right)$ into 6-well plates and grew them until they reached $80 \%-90 \%$ confluency. Cells were then incubated with $90 \%$ Dulbecco's Modified Eagle's Medium (DMEM) and 10\% Fetal Bovine Serum (FBS, \#04-001-1A, Biological Industries, Cromwell, CT, USA), $1.0 \mu \mathrm{M}$ Dexamethasone, $0.5 \mathrm{mM}$ Methylisobutylxanthine (IBMX, 3-isobutyl-1-methylxanthine, \#15879, Sigma-Aldrich, St. Louis, Missouri, USA), 1.0 $\mu \mathrm{g} / \mathrm{mL}$ insulin (\#I9278-5ML, Sigma-Aldrich, St. Louis, Missouri, USA), and 1\% PSA as start differentiation medium (SDM) for 3 days. The medium was then changed to DMEM with $1 \mu \mathrm{g} / \mathrm{mL}$ insulin, $10 \% \mathrm{FBS}, 1 \%$ PSA as maintained differentiation medium (MDM) until day 6. In order to investigate the OT effects on lipid and glucose metabolic genes, 3T3L1 adipocytes were treated with 0,10 , $30,100,150,300 \mathrm{nM}$ of OT during 6 days of differentiation (long-term) or for 24 hours after 6 days of differentiation (short-term), After OT treatments, triacylglycerol (TAG) deposition and specific RNAs and proteins were measured.

\subsection{Glucose Uptake in 3T3L1 Adipocytes}

The 3T3L1 adipocytes were treated with daily OT doses $(0,10,30,100,150$, and $300 \mathrm{nM}$ ) during differentiation for six days. At day 7, 3T3L1 adipocytes were incubated with fresh medium for 24 hours, and then cultured with glucose-free medium containing 2-NBDG (a fluorescent d-glucose analog, 2-[N-(7-nitrobenz-oxa-1,3-diazol-4-yl) amino]-2-deoxy-D-glucose) for 10 mins. The levels of glucose uptake in cells were evaluated using the Glucose Uptake Fluorometric Assay Kit (Cat. K666-100, Biovision, Milpitas, CA), according to the manufacturer's instructions.

\subsection{Synthesis of Triacylglycerol (TAG) in 3T3L1 Adipocytes}

The 3T3L1 adipocytes were seeded in 6-well plates and treated with daily OT doses $(0,10,30,100,150$, and $300 \mathrm{nM})$ during differentiation for six days. Adipocytes were collected by rubber policeman at day 6 in $500 \mu \mathrm{L}$ of cold diluted standard diluent (provided by TAG kit) for each well. After sonicating on ice and centrifugation at $10,000 \times \mathrm{g}$ for $10 \mathrm{mins}$ at $4^{\circ} \mathrm{C}$, the supernatant was collected. TAG concentration were analyzed and followed by triglyceride colorimetric assay kit (No. 10010303, Cayman Chemical, Ann Arbor, MI, USA). We added $10 \mu \mathrm{L}$ of the diluted samples to the 96 -well plates, and initiated the reaction by adding $150 \mu \mathrm{L}$ of diluted enzyme buffer solution. After carefully shaking the plates to mix, we covered the plates and incubated for 15 mins at room temperature. The absorbance is measured at $540 \mathrm{~nm}$ by a plate reader.

\subsection{Real-Time PCR for Measuring Gene Expressions}

Total RNA was extracted from cultured cells using Trizol reagent (Invitrogen, Carlsbad, CA, USA) according to the manufacturer's protocol. Total RNA was 
reverse-transcribed with random primers using the high capacity cDNA reverse-transcription reagents kit (\#4368814, ThermoFisher, Waltham, MA, USA). The mRNA expression was determined using the SYBR green reagent (ThermoFisher, Waltham, MA, USA). Real-Time PCR was performed using the Step One Plus Real-Time PCR System (ThermoFisher, Waltham, MA, USA) with the following incubation protocol: initial 7 mins at $95^{\circ} \mathrm{C}$, followed by 39 cycles of 10 secs at $95^{\circ} \mathrm{C}, 30 \operatorname{secs}$ at $60^{\circ} \mathrm{C}$, with a final extension for $1 \mathrm{~min}$ at $60^{\circ} \mathrm{C}$. The $\beta$-actin (ACTB) mRNA in the same sample served as internal control. The sequences of primers were indicated in Table 1.

\subsection{Preparation of Porcine Adipose Tissue Derived Stem Cells}

The method was that of Chen et al., 2016 [27]. Briefly, cells were isolated from adipose tissue from 7 to 9 -day old pigs using collagenase digestion. Cells were plated on six-well plates at a density of $6 \times 10^{5}$ cell per $\mathrm{cm}^{2}$. Cells were incubated until they reached 80 to $90 \%$ confluency. Cells were then differentiated in SDM for 3 days and then the medium was changed to MDM until day 6. For porcine adipocyte SDM, prepare $1 \mathrm{~L}$ of serum-free DMEM/F12 (with antibiotics of $1 \%$ PSA) containing the following: $1 \mathrm{ml}$ insulin stock $(10 \mathrm{mg} / \mathrm{ml} \mathrm{HEPES} \mathrm{buffer,} \mathrm{pH}$ 8), final concentration $=10 \mu \mathrm{g} / \mathrm{ml} ; 1 \mu \mathrm{T} \mathrm{T3}$ stock (3,3',5-Triiodo-L-thyronine, 1 $\mathrm{mM}$ in DMSO), final concentration $=1 \mathrm{nM} ; 200 \mu \mathrm{l}$ transferrin stock $(50 \mathrm{mg} / \mathrm{ml}$

Table 1. Primer set

\begin{tabular}{cccc}
\hline Genes & \multicolumn{1}{c}{ 5' to 3' $^{\prime}$} & Accession No. & Annealing Tem. $\left({ }^{\circ} \mathrm{C}\right)$ \\
\hline GLUT1-S & ACCATCTTGGAGCTGTTCCG & NM_011400 & $60^{\circ} \mathrm{C}$ \\
GLUT1-A & GCCTTCTCGAAGATGCTCGT & & \\
GLUT4-S & TTTGCACACGGCTTCCGAAC & NM_009204 & $60^{\circ} \mathrm{C}$ \\
GLUT4-A & AGTGTTCCAGTCACTCGCTG & & \\
INSR-S & CTACTGCTATGGGCTTCGGG & NM_001330056 & $60^{\circ} \mathrm{C}$ \\
INSR-A & TGGTCAGGTTGTTCCGGATG & & \\
CPT1 A-S & GCAGCAGGTGGAACTGTTTG & NM_013495 & $58.2^{\circ} \mathrm{C}$ \\
CPT1 A-A & GTGTGAGTCTGTCTCAGGGC & & \\
CPT1 B-S & GAATCCTCGACGACCCTTCC & NM_009948 & $60^{\circ} \mathrm{C}$ \\
CPT1 B-A & TGAAGAAGGTCTGACGTGCC & & \\
FABP4-S & TCACCATCCGGTCAGAGAGT & NM_024406 & $58.2^{\circ} \mathrm{C}$ \\
FABP4-A & CCAGCTTGTCACCATCTCGT & & $60^{\circ} \mathrm{C}$ \\
CHREBP-S & GCTTCAGAAGACAGCGGAGT & NM_021455 & $60^{\circ} \mathrm{C}$ \\
CHREBP-A & TCTGGTCAAAGCGCTGATGT & & \\
HSL-S & CCCCGAGATGTCACAGTCAAT & NM_001039507 & \\
HSL-A & GAATTCCCGGATCGCAGAA & & \\
ACTB-S & GCCTTCTAGCACCATGAAGA & NM_007393 & \\
ACTB-A & AGCTGATCCGCCTTTAGCTC & & \\
\hline
\end{tabular}


double distilled $\mathrm{H}_{2} \mathrm{O}$ ), final concentration $=10 \mu \mathrm{g} / \mathrm{ml} ; 100 \mu$ l dexamethasone stock (10 mM in ethanol), final conc $=1 \mu \mathrm{M} ; 100 \mu$ rosiglitazone stock $(10 \mathrm{mM}$ in DMSO), final concentration $=1 \mu \mathrm{M}$. Prepare adipocyte MDM with the same additions as the induction medium, but with omission of dexamethasone. Differentiated adipocytes were treated with $0,10,30,100,150,300 \mathrm{nM}$ OT during 6 days of differentiation or 24 hours after differentiation. After incubation with OT, adipocytes were collected for analysis of TAG concentration and mRNA expression.

\subsection{Western Blotting}

Cells were scraped from the plate and sonicated with diluted 1X RIPA Lysis Buffer (\#9806, Cell signaling, Danvers, MA, USA) containing Pierce Protease and Phosphatase Inhibitor Tablets (\#88668, ThermoFisher, Waltham, MA). The supernatant was collected at $4^{\circ} \mathrm{C}$ for 15 mins at $14,000 \times$ g. Protein levels were quantified by BCA protein assay (B6916, Sigma-Aldrich, St. Louis, Missouri, USA). For detection of the candidate proteins, cell aliquots $(9 \mu \mathrm{g})$ were analyzed by electrophoresis for 75 mins at $100 \mathrm{~V}$ in 10\% SDS-polyacrylamide gels using a Mini-PROTEAN Tetra Cell system (BioRad, Hercules, CA). Proteins were transferred to a polyvinylidene difluoride membrane at $400 \mathrm{~mA}$ for 75 mins on ice using a TE22 Mighty Small Transphor Unit (Hoefer, Holliston, MA). Nonspecific binding sites were blocked with TBS (20 mM Tris- $\mathrm{HCl}, \mathrm{pH}$ 7.4, $140 \mathrm{mM}$ $\mathrm{NaCl}$ ), containing $5 \%(\mathrm{w} / \mathrm{v})$ non-fat dry milk and $0.1 \%$ Tween 20 for 1 hour at room temperature. Membranes were incubated with primary antibody overnight at $4^{\circ} \mathrm{C}$. Then, membranes were incubated at room temperature for 1 hour with secondary antibody. Finally, the Immobilon ${ }^{\mathrm{TM}}$ Western Chemiluminescent HRP Substrate was applied (Millipore, Billerica, MA). Membranes were analyzed by densitometry using a BioSpectrum ${ }^{\mathrm{TM}} 500$ Imaging System Motorized Platform (UVP, Upland, CA). The sizes of proteins were estimated using a broad range molecular mass standard (20 to $250 \mathrm{kDa}$ ) from Fermentas (\#SM0671, ThermoFisher, Waltham, MA). Between every blocking step and antibody incubations, TBS containing 0.1\% Tween-20 (TBST) was used for membrane washes every 15 mins with washes repeated three times. Glut4 (\#2213, Cell signaling, Danvers, MA, USA), Phospho-AKT (Ser473) (\#9271, Cell signaling, Danvers, MA, USA), and AKT (\#9272, Cell signaling, Danvers, MA, USA) antibodies were prepared with 5\% BSA in TBST (dilution 1/1000), and the secondary antibody goat anti-rabbit IgG-HRP (sc-2004, Santa Cruz Biotechnology, Dallas, Texas, USA) was prepared with $5 \%$ nonfat dry milk in TBST (dilution 1/5000); and goat anti-mouse secondary antibody (sc-2005, Santa Cruz Biotechnology, Dallas, Texas, USA) was prepared with $5 \%$ gelatin in TBST (dilution 1/10,000).

\subsection{Statistical Analysis}

All data are presented as the mean \pm SEM. Multiple comparisons were performed using ANOVA followed by the Turkey test using GraphPad Prism 5 (GraphPad software Inc., San Diego, CA, USA.). 


\section{Abbreviations and Acronyms}

CHREBP: carbohydrate response element binding protein; CPT1 1 : carnitine palmitoyltransferase-I $\alpha$; CPT $1 \beta$ : carnitine palmitoyltransferase-I $\beta$; FABP4: fatty acid binding protein 4; GLUT1: glucose transporters 1; GLUT4: glucose transporters 4; HSL: hormone sensitive lipase; INSR: insulin receptor; OT: oxytocin; SDM: start differentiation medium; TAG: triacylglycerol.

\section{Results}

\subsection{Effects of Oxytocin on Adipocyte Differentiation and Lipid Accumulation}

The 3T3L1 cell line underwent a differentiation program of 3 days in SDM followed by 3 days in MDM. Triacylglycerol (TAG) accumulation was not affected by short-term (24 hours) OT treatment (Figure 1(a)), but was increased by long-term (6 days) treatment with 100 and $150 \mathrm{nM}$ OT treatment (Figure 1(b)). The mRNA expressions of CPT- $1 \alpha$, the rate-limiting enzyme responsible for mitochondrial fatty acid oxidation, and FABP4, a fatty acid binding protein were both decreased by 100 and $150 \mathrm{nM}$ OT after short-term incubation (Figure $1(\mathrm{c}))$. Only CPT- $1 \alpha$ was decreased after long term treatment with $150 \mathrm{nM}$ OT (Figure $1(\mathrm{~d})$ ). CPT- $1 \beta$ is a muscle isoform of CPT- $1 \alpha$, and we have confirmed that there was no CPT- $1 \beta$ expression in adipocytes (data not indicated). Expression of hormone sensitive lipase (HSL) mRNA was not altered by short-or long-term incubation with OT (Figure 1(d)). These results indicated that stimulation of OT may decrease fatty acid oxidation and attenuate the ability of binding fatty acids.

In pig adipose tissue derived stem cells (pADSCs), TAG was not changed after short-or long-term incubation with OT (Figure 2(a) and Figure 2(b)). The HSL mRNA was decreased with short-term incubation with 30 to $300 \mathrm{nM} \mathrm{OT} \mathrm{(Figure}$ 2(a)) and by incubation with 150 and $300 \mathrm{nM}$ OT after long-term incubation (Figure 2(b)). The mRNA levels of CPT-1 $\alpha$ and FABP4 were not changed (Figure 2(a) and Figure 2(b)). The data suggested OT treatment may affect lipid accumulation through an inhibitory effect on HSL mRNA expression in pig adipocytes.

\subsection{The Effect of Oxytocin on Glucose Utilization in 3T3L1 Adipocytes}

In differentiated 3T3L1 adipocytes, glucose uptake was significantly elevated in the presence of 10 to $300 \mathrm{nM}$ OT (Figure 3(a)). The main insulin-sensitive glucose transporter responsible for glucose uptake in adipocytes is GLUT4, not GLUT1; 30 nM OT induced both GLUT4 mRNA (Figure 3(b)) and protein expression (Figure $3(\mathrm{c})$ ). OT treatments may enhance glucose utilization through increase the expression of glucose transporters in adipocytes.

The carbohydrate response element binding protein (ChREBP), a transcription factor coupling hepatic glucose utilization and lipid synthesis, was not 


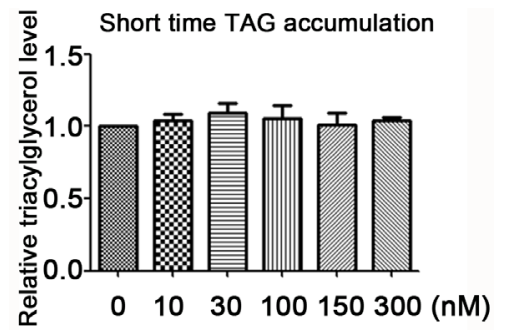

(a)

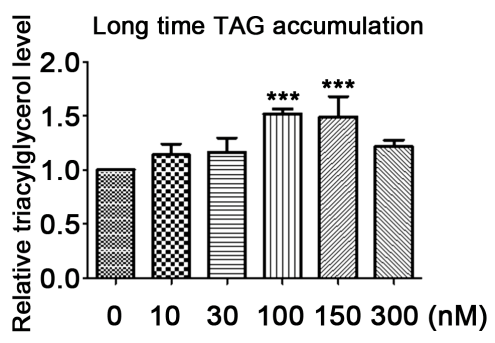

(b)

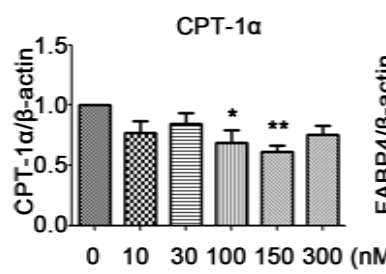

FABP4

HSL

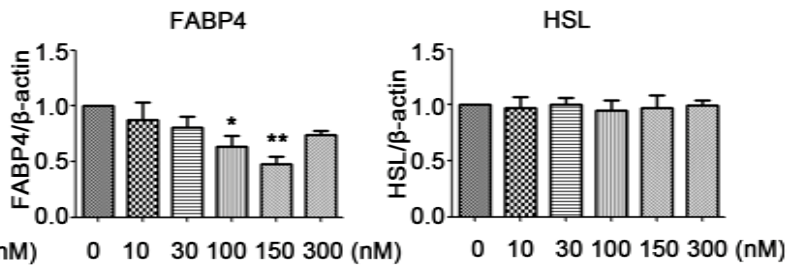

(c)
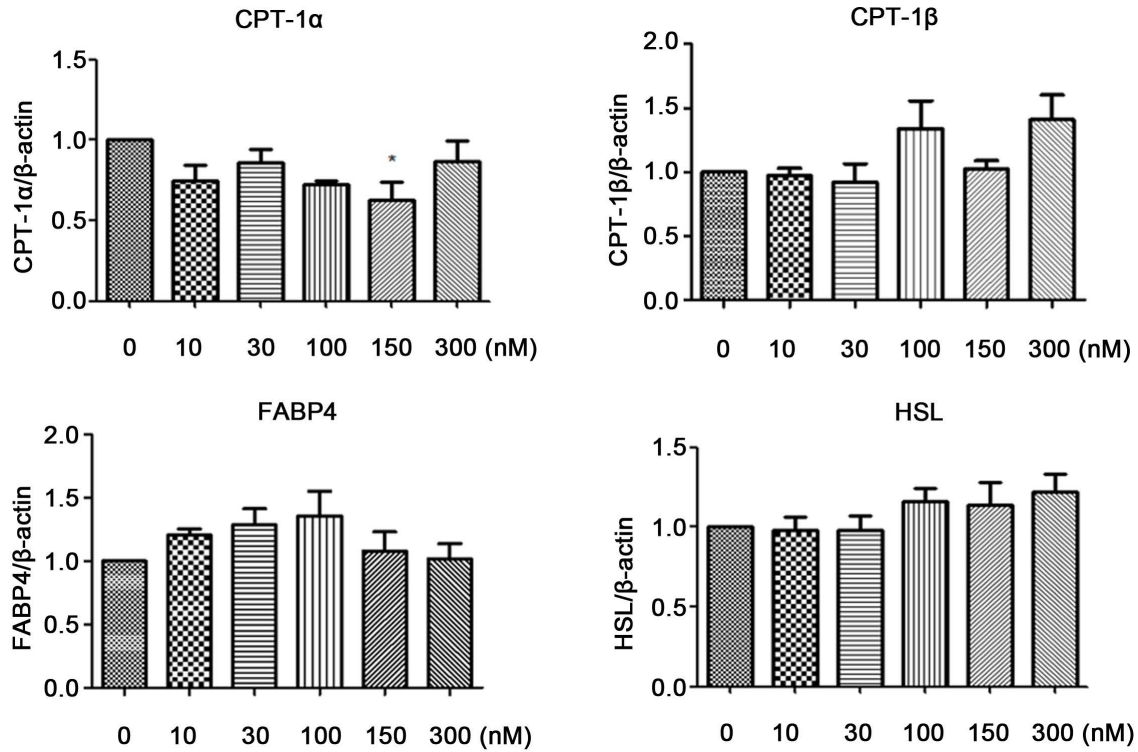

(d)

Figure 1. The short- and long-term effects of OT treatment on 3T3L1 adipocytes. The OT concentration was indicated on the x-axis. (A) The accumulation of TAG in 3T3L1 adipocytes after short-term (24 hours) treatment. (B) The accumulations of TAG in 3T3L1 adipocytes after long-term (144 hours) treatment. (C) The mRNA expressions in 3T3L1 adipocytes after short-term treatment (24 hours). (D) The mRNA expressions in 3T3L1 adipocytes after long-term (144 hours) treatment. Values were expressed as mean \pm SEM. One-way ANOVA with the Tukey post hoc test was used to examine the treatment effect. ${ }^{*} P \leq 0.05,{ }^{* *} P \leq 0.01,{ }^{* *} P \leq 0.001, \mathrm{~N} \geq 6$. 

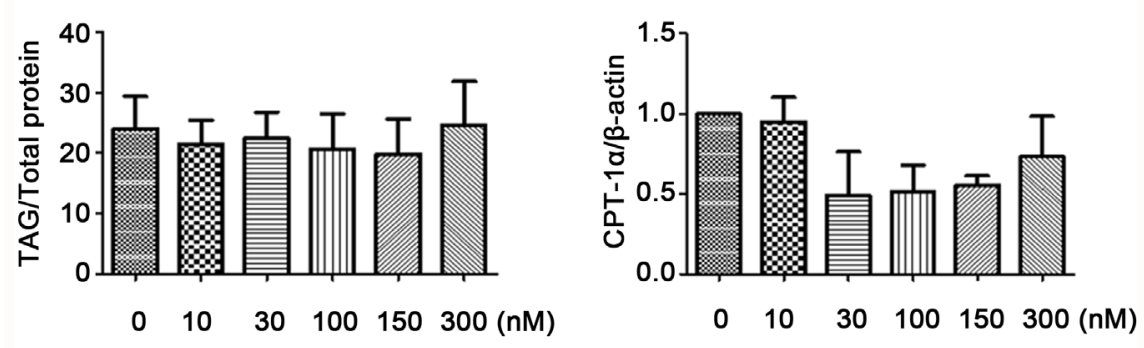

FABP4

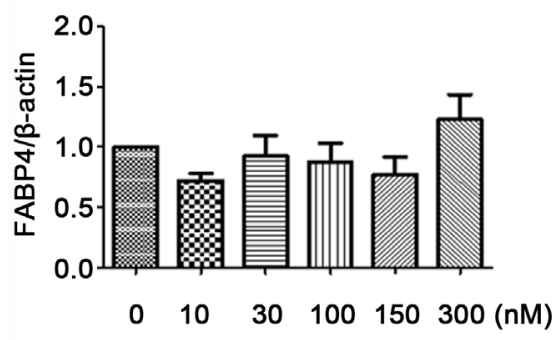

HSL

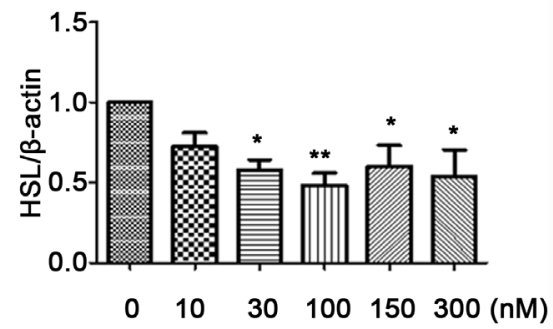

(a)
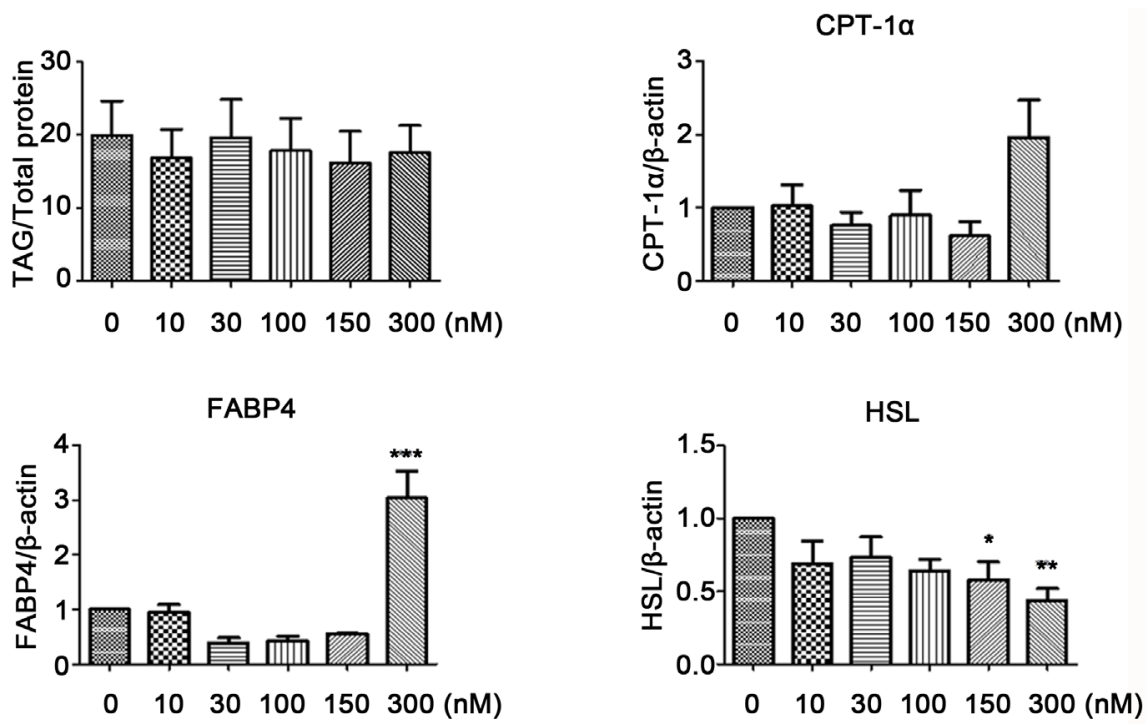

(b)

Figure 2. TAG accumulation and mRNA expressions in pig adipocytes after short-term (24 hours, A) and long-term (144 hours, B) treatment with OT. Values were expressed as mean \pm SEM. One-way ANOVA with the Tukey post hoc test was used to examine the treatment effect. ${ }^{*} P \leq 0.05,{ }^{* *} P \leq 0.01 . \mathrm{N} \geq 6$.

changed after OT treatment (Figure 3(b)). For determining whether insulin downstream pathway is activated by OT treatments, the insulin receptor mRNA (INSR) was examined. The result showed that INSR mRNA was not affected by OT (Figure 3(b)).

In addition, there was significantly less AKT phosphorylation at $150 \mathrm{nM}$ OT in 3T3L1 adipocytes (Figure 4). Thus, OT did not affect the mRNA concentration of the INSR or the upstream insulin signaling pathway (AKT/PKB). 


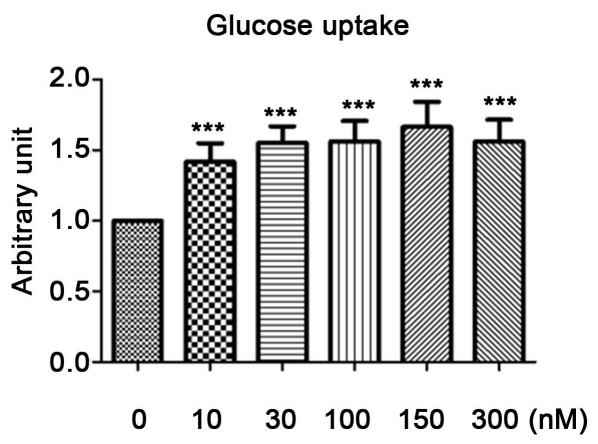

(a)
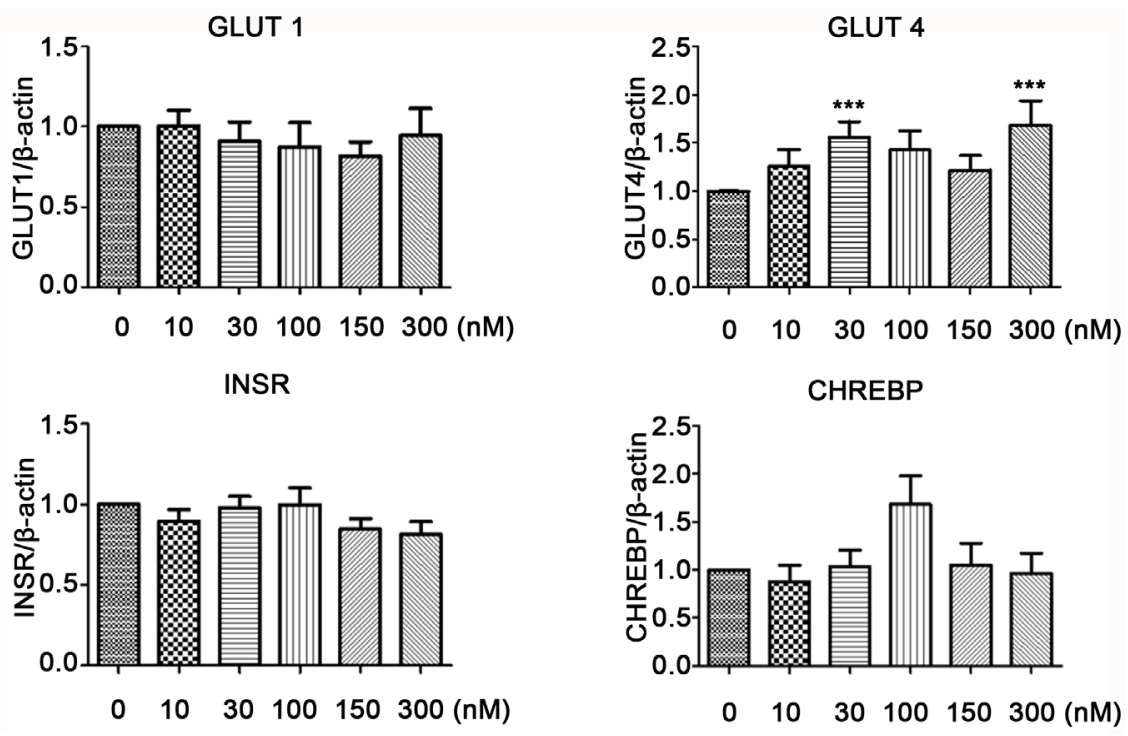

(b)

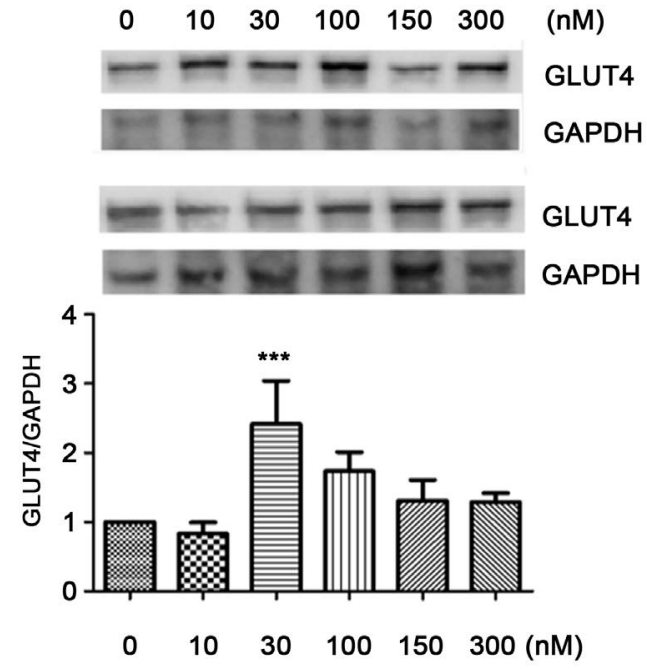

(c)

Figure 3. Long-term treatment (6 days) of 3T3L1 cells with OT. (a) Glucose uptake; (b) The glucose utilization related gene expressions; (c) The protein expression levels of GLUT4. The upper panel was the western blotting results. GAPDH (glyceraldehyde 3 phosphate dehydrogenase) was used as loading control. Values were expressed as mean \pm SEM. One-way ANOVA with the Tukey post hoc test was used to examine the treatment effect. ${ }^{\star} P \leq 0.05,{ }^{*} P \leq 0.01,{ }^{* *} P \leq 0.001 . \mathrm{N} \geq 4$. 


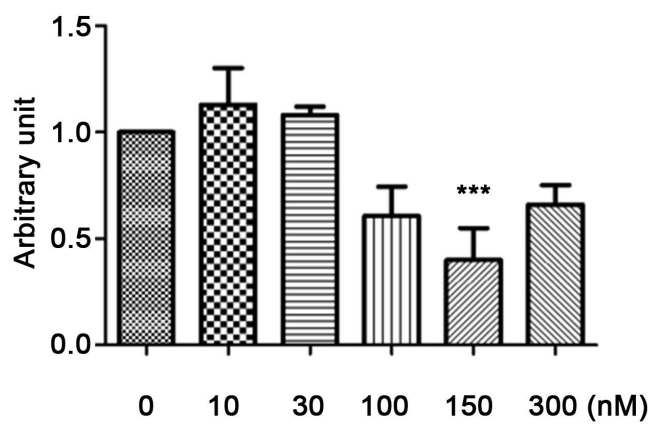

Figure 4. The phosphorylation of AKT/PKB was in-activated by $150 \mathrm{nM} \mathrm{OT}$ at day 6 in 3T3L1 adipocytes. Values were expressed as mean \pm SEM. One-way ANOVA with the Tukey post hoc test was used to examine the treatment effect. ${ }^{* * *} P \leq 0.001$. $\mathrm{N} \geq 4$.

\section{Discussion}

Short-term treatment of 3T3L1 cells with OT decreased expression of CPT-1 $\alpha$ and FABP4 mRNA, but did not change the TAG concentration. Long-term treatment with OT increased TAG concentration in adipocytes and decreased CPT- $1 \alpha$ expression, suggesting decreased fatty acid oxidation to increase TAG deposition. The HSL mRNA expression was inhibited by OT both in short- and long-term treatment in porcine differentiated adipocytes suggesting that OT increased TAG concentration by decreasing fatty acid oxidation and inhibiting lipolysis. Incubation with OT enhanced the absorption of glucose in adipocytes and up-regulated GLUT4 transporter mRNA expression, but did not affect the mRNA concentrations of the INSR or ChREBP and did not modulate the upstream insulin signaling pathway, AKT/PKB.

Previous studies indicated very mixed results for OT effects in adipocytes. For example, OT increased not only lipogenesis in ex vivo experiments with adipose tissue or cell culture systems [28] [29], but also lipolysis in other cells as well [30] [32]. It was demonstrated that OT suppressed adipocyte differentiation [31], whereas the OTR mRNA expression was increased during adipocyte differentiation. It was also shown that the OTR expressions in 14-week-old mice were significantly increased in adipose tissues (subcutaneous and epididymal) compared to those of 7-week-old mice [32]. However, our results suggested OT increased TAG content in adipocytes through decreasing the expression of genes related to fatty acid oxidation and lipolysis. Such effects are similar to the biological effects of insulin surges.

The glucose oxidation was increased along with increased pyruvate dehydrogenase activity under OT treatment [33] [34]. Treatment of OT induced AMP protein kinase (AMPK) pathway on mouse skeletal muscle cells [35], and OTinduced glucose uptake was blocked by either STO-609 or Compound C, indicating AMPK and calcium play important roles in the function of OT in mediating glucose uptake. In consistency with these observations, our data showed that long-term OT treatment increased the expression of GLUT4 which would result in increase of the glucose uptake in adipocytes. 
There are mixed evidences for several pathways to influence the insulin-like effects of OT. Modulation of $\mathrm{Ca}^{2+}$ and the AMPK pathway were involved in skeletal muscle [35] and in cardiomyocytes [8]. Inositol phosphate did not appear to be involved [36]. In myometrial cells, protein synthesis was stimulated, apparently via an increase in protein kinase C activity [37] [38]. OT was bound to OT receptors and activated the MAP kinases ERK1/2 pathway through Gaq/Gai, enhancing the novel and atypical PKC isoforms in hTERT-C3 cells [39]. The present experiments with OT treatments in vitro suggested participation of other pathways besides the AKT/PKB signaling pathway was to modulate fatty acid metabolism, glucose uptake and oxidation and energy homeostasis.

There is no direct evidence for OT regulating pathways on lipid or carbohydrate metabolisms in adipocytes. The mechanisms for OT effects on adipocytes may be species or even tissue specific. Thus, extensive exploration of various mechanisms is required to discern mechanisms for OT effects in adipocytes.

\section{Acknowledgements}

The authors would like to express our gratitude to the laboratory members for all their help and input during this study. This work was supported by the Ministry of Science and Technology, under Grant NSC 100-2923-B-002-005-MY3 in Taiwan. We declare that the experiments comply with the current Taiwan laws, the place in which the experiments were performed. There is no conflict of interest.

\section{References}

[1] Katoh, A., Fujihara, H., Ohbuchi, T., Onaka, T., Hashimoto, T., Kawata, M., Suzuki, H. and Ueta, Y. (2011) Highly Visible Expression of an Oxytocin-Monomeric Red Fluorescent Protein 1 Fusion Gene in the Hypothalamus and Posterior Pituitary of Transgenic Rats. Endocrinology, 152, 2768-2774. https://doi.org/10.1210/en.2011-0006

[2] Insel, T.R., Young, L. and Wang, Z. (1997) Central Oxytocin and Reproductive Behaviours. Reviews of Reproduction, 2, 28-37. https://doi.org/10.1530/ror.0.0020028

[3] Jin, D., Liu, H.X., Hirai, H., Torashima, T., Nagai, T., Lopatina, O., Shnayder, N.A., Yamada, K., Noda, M., Seike, T., Fujita, K., Takasawa, S., Yokoyama, S., Koizumi, K., Shiraishi, Y., Tanaka, S., Hashii, M., Yoshihara, T., Higashida, K., Islam, M.S., Yamada, N., Hayashi, K., Noguchi, N., Kato, I., Okamoto, H., Matsushima, A., Salmina, A., Munesue, T., Shimizu, N., Mochida, S., Asano, M. and Higashida, H. (2007) CD38 Is Critical for Social Behaviour by Regulating Oxytocin Secretion. Nature, 446, 41-45. https://doi.org/10.1038/nature05526

[4] Caldwell, H.K., Stephens, S.L. and Young, W.S. (2009) Oxytocin as a Natural Antipsychotic: A Study Using Oxytocin Knockout Mice. Molecular Psychiatry, 14, 190196. https://doi.org/10.1038/sj.mp.4002150

[5] Quirin, M., Kuhl, J. and Düsing, R. (2011) Oxytocin Buffers Cortisol Responses to Stress in Individuals with Impaired Emotion Regulation Abilities. Psychoneuroendocrinology, 36, 898-904. https://doi.org/10.1016/j.psyneuen.2010.12.005

[6] Gutkowska, J., Jankowski, M., Mukaddam-Daher, S. and McCann, S.M. (2000) Oxytocin Is a Cardiovascular Hormone. Brazilian Journal of Medical and Biological Research, 33, 625-633. https://doi.org/10.1590/S0100-879X2000000600003 
[7] Ondrejcakova, M., Ravingerova, T., Bakos, J., Pancza, D. and Jezova, D. (2009) Oxytocin Exerts Protective Effects on in Vitro Myocardial Injury Induced by Ischemia and Reperfusion. Canadian Journal of Physiology and Pharmacology, 87, 137-142. https://doi.org/10.1139/Y08-108

[8] Florian, M., Jankowski, M. and Gutkowska, J. (2010) Oxytocin Increases Glucose Uptake in Neonatal Rat Cardiomyocytes. Endocrinology, 151, 482-491.

https://doi.org/10.1210/en.2009-0624

[9] Gutkowska, J. and Jankowski, M. (2012) Oxytocin Revisited: Its Role in Cardiovascular Regulation. Journal of Neuroendocrinology, 24, 599-608. https://doi.org/10.1111/j.1365-2826.2011.02235.x

[10] Kimura, T., Tanizawa, O., Mori, K., Brownstein, M.J. and Okayama, H. (1992) Structure and Expression of a Human Oxytocin Receptor. Nature, 356, 526-529. https://doi.org/10.1038/356526a0

[11] Zingg, H.H. and Laporte, S.A. (2003) The Oxytocin Receptor. Trends in Endocrinology and Metabolism, 14, 222-227. https://doi.org/10.1016/S1043-2760(03)00080-8

[12] Stock, S., Granstrom, L., Backman, L., Matthiesen, A.S. and Uvnäs-Moberg, K. (1989) Elevated Plasma Levels of Oxytocin in Obese Subjects before and after Gastric Banding. International Journal of Obesity, 13, 213-222.

[13] Northway, M.G., Morris, M., Geisinger, K.R. and MacLean, D.B. (1989) Effects of a Gastric Implant on Body Weight and Gastrointestinal Hormones in Cafeteria Diet Obese Rats. Physiology Behavior, 45, 331-335.

https://doi.org/10.1016/0031-9384(89)90135-2

[14] Schroeder, M., Zagoory-Sharon, O., Shbiro, L., Marco, A., Hyun, J., Moran, T.H., Bi, S. and Weller, A. (2009) Development of Obesity in the Otsuka Long-Evans Tokushima Fatty Rat. American Journal of Physiology-Regulatory, Integrative and Comparative Physiology, 297, R1749-1760. https://doi.org/10.1152/ajpregu.00461.2009

[15] Takayanagi, Y., Kasahara, Y., Onaka, T., Takahashi, N., Kawada, T. and Nishimori, K. (2008) Oxytocin Receptor-Deficient Mice Developed Late-Onset Obesity. Neuroreport, 19, 951-955. https://doi.org/10.1097/wnr.0b013e3283021ca9

[16] Camerino, C. (2009) Low Sympathetic Tone and Obese Phenotype in Oxytocin-Deficient Mice. Obesity, 17, 980-984. https://doi.org/10.1038/oby.2009.12

[17] Maejima, Y., Iwasaki, Y., Yamahara, Y., Kodaira, M., Sedbazar, U. and Yada, Y. (2011) Peripheral Oxytocin Treatment Ameliorates Obesity by Reducing Food Intake and Visceral Fat Mass. Aging, 3, 1169-1177. https://doi.org/10.18632/aging.100408

[18] Morton, G.J., Thatcher, B.S., Reidelberger, R.D., Ogimoto, K., Wolden-Hanson, T., Baskin, D.G., Schwartz, M.W. and Blevins, J.E. (2012) Peripheral Oxytocin Suppresses Food Intake and Causes Weight Loss in Diet-Induced Obese Rats. American Journal of Physiology—Endocrinology and Metabolism, 302, E134-E144. https://doi.org/10.1152/ajpendo.00296.2011

[19] Altirriba, J., Poher, A.L., Caillon, A., Arsenijevic, D., Veyrat-Durebex, C., Lyautey, J., Dulloo, A. and Rohner-Jeanrenaud, F. (2014) Divergent Effects of Oxytocin Treatment of Obese Diabetic Mice on Adiposity and Diabetes. Endocrinology, 155, 4189-4201. https://doi.org/10.1210/en.2014-1466

[20] Eckertova, M., Ondrejcakova, M., Krskova, K., Zorad, S. and Jezova, D. (2011) Subchronic Treatment of Rats with Oxytocin Results in Improved Adipocyte Differentiation and Increased Gene Expression of Factors Involved in Adipogenesis. British Journal of Pharmacology, 162, 452-463. 
https://doi.org/10.1111/j.1476-5381.2010.01037.x

[21] Hanif, K., Lederis, K., Hollenberg, M.D. and Goren, H.J. (1982) Inability of Oxytocin to Activate Pyruvate Dehydrogenase in the Brattleboro Rat. Science, 216, 10101012. https://doi.org/10.1126/science.7079746

[22] Gimpl, G. and Fahrenholz, F. (2001) The Oxytocin Receptor System: Structure, Function, and Regulation. Physiological Reviews, 81, 629-683.

[23] Dunning, B.E., Moltz, J.H. and Fawcett, C.P. (1984) Modulation of Insulin and Glucagon Secretion from the Perfused Rat Pancreas by the neurohypophysial Hormones and by Desamino-D-Arginine Vasopressin (DDAVP). Peptides, 5, 871-875. https://doi.org/10.1016/0196-9781(84)90109-8

[24] Gao, Z.Y., Drews, G. and Henquin, J.C. (1991) Mechanisms of the Stimulation of Insulin Release by Oxytocin in Normal Mouse Islets. Biochemical Journal, 276, 169-174. https://doi.org/10.1042/bj2760169

[25] Zhang, G. and Cai, D. (2011) Circadian Intervention of Obesity Development via Resting-Stage Feeding Manipulation or Oxytocin Treatment. The American Journal of Physiology - Endocrinology and Metabolism, 301, E1004-1012. https://doi.org/10.1152/ajpendo.00196.2011

[26] Liepinsh, E., Vilskersts, R., Skapare, E., Svalbe, B., Kuka, J., Cirule, H., Pugovics, O., Kalvinsh, I. and Dambrova, M. (2008) Mildronate Decreases Carnitine Availability and Up-Regulates Glucose Uptake and Related Gene Expression in the Mouse Heart. Life Science, 83, 613-619. https://doi.org/10.1016/j.lfs.2008.08.008

[27] Chen, Y.J., Liu, H.Y., Chang, Y.T., Cheng, Y.H., Mersmann, H.J., Kuo, W.H. and Ding, S.T. (2016) Isolation and Differentiation of Adipose-Derived Stem Cells from Porcine Subcutaneous Adipose Tissues. Journal of Visualized Experiments, 109, e53886. https://doi.org/10.3791/53886

[28] Goren, H.J., Hanif, K., Dudley, R., Hollenberg, M.D. and Lederis, K. (1986) Adenosine Modulation of Fat Cell Responsiveness to Insulin and Oxytocin. Regulatory Peptides, 16, 125-134. https://doi.org/10.1016/0167-0115(86)90056-X

[29] Eriksson, H., Bjorgell, P., Akerlund, M., Hauksson, A. and Melin, P. (1990) Effects of a Tocolytic Oxytocin Analogue on Lipid and Carbohydrate Metabolism. Gynecologic and Obstetric Investigation, 29, 97-100. https://doi.org/10.1159/000293310

[30] Deblon, N., Veyrat-Durebex, C., Bourgoin, L., Caillon, A., Bussier, A.L., Petrosino, S., Piscitelli, F., Legros, J.J., Geenen, V. and Foti, M. (2011) Mechanisms of the Anti-Obesity Effects of Oxytocin in Diet-Induced Obese Rats. PLoS One, 6, e25565. https://doi.org/10.1371/journal.pone.0025565

[31] Wilson, E.J. and Hollenberg, M.D. (1987) Effects of Oxytocin and Vasopressin on the Preadipocyte 3T3-F442A Cell Line. Biochemistry and Cell Biology, 65, 211-218. https://doi.org/10.1139/o87-027

[32] Yi, K.J., So, K.H., Hata, Y., Suzuki, Y., Kato, D., Watanabe, K., Aso, H., Kasahara, Y., Nishimori, K., Chen, C., Katoh, K. and Roh, S.G. (2015) The Regulation of Oxytocin Receptor Gene Expression during Adipogenesis. Journal of Neuroendocrinology, 27, 335-342. https://doi.org/10.1111/jne.12268

[33] Mukherjee, S.P. and Mukherjee, C. (1982) Stimulation of Pyruvate Dehydrogenase activity in Adipocytes by Oxytocin: Evidence for Mediation of the Insulin-Like Effect by Endogenous Hydrogen Peroxide Independent of Glucose Transport. Archives of Biochemistry and Biophysics, 214, 211-222. https://doi.org/10.1016/0003-9861(82)90024-8

[34] Altirriba, J., Poher, A.L. and Rohner-Jeanrenaud, F. (2015) Chronic Oxytocin Administration as a Treatment against Impaired Leptin Signaling or Leptin Resistance 
in Obesity. Frontiers in Endocrinology, 6, 119.

https://doi.org/10.3389/fendo.2015.00119

[35] Lee, E.S., Uhm, K.O., Lee, Y.M., Kwon, J., Park, S.H. and Soo, K.H. (2008) Oxytocin Stimulates Glucose Uptake in Skeletal Muscle Cells through the Calcium-CaMKKAMPK Pathway. Regulatory Peptides, 151, 71-74.

https://doi.org/10.1016/j.regpep.2008.05.001

[36] Augert, G. and Exton, J.H. (1988) Insulin and Oxytocin Effects on Phosphoinositide Metabolism in Adipocytes. The Journal of Biological Chemistry, 263, 3600-3609.

[37] Devost, D., Girotti, M., Carrier, M.E., Russo, C. and Zingg, H.H. (2005) Oxytocin Induces Dephosphorylation of Eukaryotic Elongation Factor 2 in Human Myometrial Cells. Endocrinology, 146, 2265-2270. https://doi.org/10.1210/en.2004-1428

[38] Devost, D., Carrier, M.E. and Zingg, H.H. (2008) Oxytocin-Induced Activation of Eukaryotic Elongation Factor 2 in Myometrial Cells Is Mediated by Protein Kinase C. Endocrinology, 149, 131-138. https://doi.org/10.1210/en.2007-0548

[39] Wrzal, P.K., Goupil, E., Laporte, S.A., Hébert, T.E. and Zingg, H.H. (2012) Functional Interactions between the Oxytocin Receptor and the $\beta 2$-Adrenergic Receptor: Implications for ERK1/2 Activation in Human Myometrial Cells. Cellular Signalling, 24, 333-341. https://doi.org/10.1016/j.cellsig.2011.09.019

\section{Scientific Research Publishing}

Submit or recommend next manuscript to SCIRP and we will provide best service for you:

Accepting pre-submission inquiries through Email, Facebook, LinkedIn, Twitter, etc. A wide selection of journals (inclusive of 9 subjects, more than 200 journals)

Providing 24-hour high-quality service

User-friendly online submission system

Fair and swift peer-review system

Efficient typesetting and proofreading procedure

Display of the result of downloads and visits, as well as the number of cited articles

Maximum dissemination of your research work

Submit your manuscript at: http://papersubmission.scirp.org/

Or contact jbise@scirp.org 